Accepted

20. 06. 2020

Revised

07. 09. 2020

Published

29. 10.2020

Keywords

maternal

mortality

ratio,

adolescent

pregnancy,

haemorrhage,

pre-eclampsia/eclampsia, the Republic of

Benin.

\section{TRENDS ON MATERnAL MORTALITY IN THE REPUBLIC OF BENIN AND COMPARISON WITH THE NEIGHBORING COUNTRIES}

\author{
Romeo Konnon, SAid SEMyatov, MuHAmmednazar \\ SOYUNOV, ZALINA SOKHOVA \& TATEVIK ZULUMYAN \\ Peoples' Friendship University of Russia (RUDN University), Medical Institute, \\ Department of Obstetrics and Gynecology with the course of perinatology, Moscow, \\ Russian Federation. \\ E-mail:konnon_s@pfur.ru, semyatov_sm@ pfur.ru, soyunov_ma@ppur.ru, \\ sokhova_zm@pfur.ru, zulumyan_tn@pfur.ru. \\ CORRESPONDING AUTHOR \\ konnon_s@pfur.ru
}

Abstract The maternal mortality ratio in the Republic of Benin in 2015 was still high - 405 per 100,000 live births. The delay in consultation and timely treatment, unavailability of medical facilities and lack of skilled care are the principal factors contributing to maternal deaths in Benin. Consequently, the rate of such preventable causes of maternal deaths like obstetric haemorrhage $(38.40$ percent and preeclampsia/eclampsia (14.30 percent) remains high in the country, and even HIV continued being one of the indirect causes of maternal deaths in 2017 - one percent. High rate of complications associated with pregnancy and birth in adolescent girls is another cause of maternal deaths in the Republic of Benin. Despite the efforts of the Government aimed at improving health care, it is unlikely that we will achieve the United Nations Sustainable Development Goals 3.1. - the reduction of maternal mortality ratio to less than 70 per 100,000 live births by 2030 . 


\section{$1 \quad$ Introduction}

According to the World Health Organization (WHO) "Maternal death (MD) is the death of a woman while pregnant or within 42 days of termination of pregnancy, irrespective of the duration and site of the pregnancy, from any cause related to or aggravated by the pregnancy or its management, but not from accidental or incidental causes". According to the WHO, every day in 2017, approximately 810 women (global estimates of 295,000 deaths) died worldwide from preventable causes related to pregnancy and childbirth. However, based on the WHO data, it is important to emphasize that between 2000 and 2017, the maternal mortality ratio (MMR, number of MD per 100,000 live births (lb)) dropped by 38.4 percent worldwide - from 342 in 2000 to 211 in 2017 respectively. The average annual rate of reduction (ARR) in global MMR during the period 2000-2017 was 2.9 percent. Most of MD (94 percent) occurred in low and lower-middle-income countries, and most of them could have been prevented. Sub-Saharan Africa (SSA, includes the Republic of Benin) and Southern Asia accounted for the highest rate approximately 86 percent $(254,000)$ of the estimated global MD in 2017. SSA alone accounted for roughly 66 percent $(196,000)$, while Southern Asia accounted for nearly 20 percent $(58,000)$ of MD in 2017 (WHO, 2019). Subsequently, SSA was the only region with very high MMR in 2017, estimated at 542. Unfortunately, the MMR is still unacceptably high in the Republic of Benin - 397 in 2017. A total of 1,600 maternal deaths were reported in the country in 2017.

According to global causes of MD, nearly 73 percent of all MD between 2003 and 2009 were due to direct obstetric causes whereas deaths due to indirect causes accounted for 27.5 percent of all deaths from known causes (Say et al., 2014: e327). The authors revealed that haemorrhage is the leading obstetric direct cause of MD worldwide - 27.1 percent, of which more than two-thirds are classified as postpartum haemorrhage. Hypertension is the second most common direct cause of MD worldwide - 14.0 percent. Maternal mortality due to sepsis is 10.7 percent, while abortion accounts for 7.9 percent, and embolism and other direct causes account for 12.8 percent (Say et al., 2014: e327). Particular emphasis should be placed on the proportion of complications during adolescent pregnancy and childbirth in MMR. Adolescent girls, especially those aged 10-14, facing a higher risk of complications and death as a result of pregnancy than other women, constitute a vulnerable social group. 
The WHO data showed that the overall proportion of deaths to women of reproductive age (15-49 years) that are due to maternal causes was estimated at 9.2 percent in 2017 - down by 26.3 percent since 2000 , and this means that compared with other causes of death to women of reproductive age, the fraction attributed to maternal causes is decreasing (WHOa, 2019: $\mathrm{x}$ ).

In light of the above, we analyzed trends in maternal mortality and estimates of the causes of MD in the Republic of Benin during 1995-2017 and gave recommendations for achieving the United Nations (UN) Sustainable Development Goals (SDG) 3.1.

\section{Trends over time}

High MMR (405 deaths per 100,000 lb) observed in the Republic of Benin in 2015 meant that the country was very far from achieving the Millennium Development Goal (MDG) 5A - a reduction of MMR at least by three quarters between 1990 and 2015, i.e. for Benin from 576 to 144 MD per 100,000 lb between 1990 and 2015. Thus, the Republic of Benin had achieved only a reduction in MMR of about 30 percent, and over the same period the ARR was 1.4 (WHO, 2015: 70). This means that unfortunately Benin had made "no progress". In contrast, such African countries like Cabo Verde (from MMR of 256 to 42 between 1990 and 2015 - 83.6 percent of reduction) and Rwanda (from MMR of 1,300 to 290 between 1990 and 2015 - 77.7 percent of reduction) were categorized as having "achieved MDG 5A" in 2015, while, surprisingly for the same period, South Africa faced the worst result in Africa with an increase in MMR of 27,8 percent (from MMR of 108 to 138 between 1990 and 2015) (WHO, 2015: 71, 75).

Between 2000 and 2017, SSA achieved a substantial reduction in MMR by 38.7 percent, which is comparable with worldwide reduction -38.4 percent for the same period (WHOa, 2019: 83). At the same time in the Republic of Benin, a decline in MMR (23.65 percent, from 520 to 397) was noted only between 2000 and 2017, but it was also between 1990 and 2000 (fig. 1). 


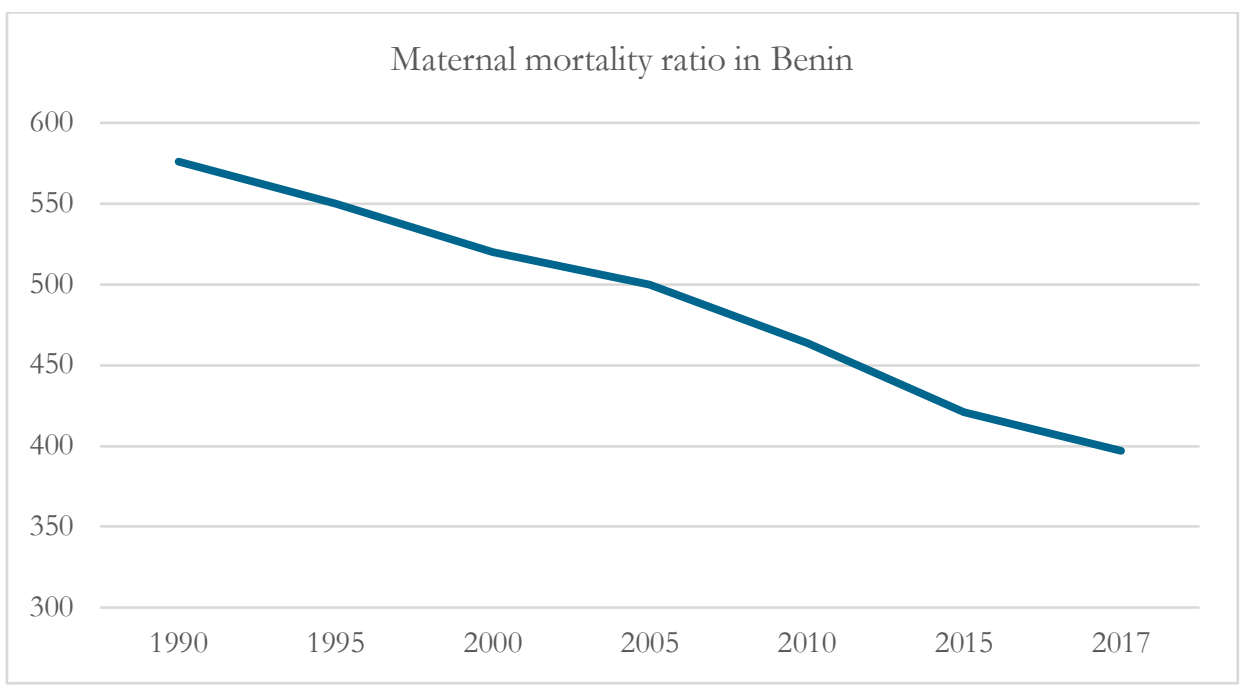

Figure 1: Dynamics of maternal mortality ratio in Benin

Source: WHO, 2015: 70; WHOa, 2019: 99.

WHO data showed that in the Republic of Benin, the reduction of 23.65 percent in MMR between 2000 and 2017 was comparable with that in Latin America and the Caribbean - 23.1 percent (from an MMR of 96 in 2000 to 74 in 2017), while it was 1.62, 1.64, 2.46 and 2.48 times lower than in the World (38.4 percent, MMR from 342 to 211 between 2000 and 2017), SSA (38.7 percent, MMR from 870 to 533 between 2000 and 2017), Eastern Europe and Central Asia (58.2 percent, MMR from 45 to 19 between 2000 and 2017), South Asia (58.7 percent, MMR from 395 to 163 between 2000 and 2017), respectively (WHOa, 2019: 83).

The average MMR in 2017 was different in the regions of SSA - 550 in Western, 475 in Central, 458 in Eastern and 286 in Southern. At the same time, the highest reduction MMR (49 percent) between 2000 and 2017 was observed in the Eastern region, while it was comparable in the Western, Central and Southern regions about 36 percent, 38 percent and 39 percent, respectively. The analysis in different regions of SSA (fig. 2) shows that the MMR still remains extremely high in three SSA countries - South Sudan $(1,150)$, Chad $(1,140)$ and Sierra Leone $(1,120)$, while very high MMR was observed in 15 countries (from 509 in Niger to 917 in Nigeria). 


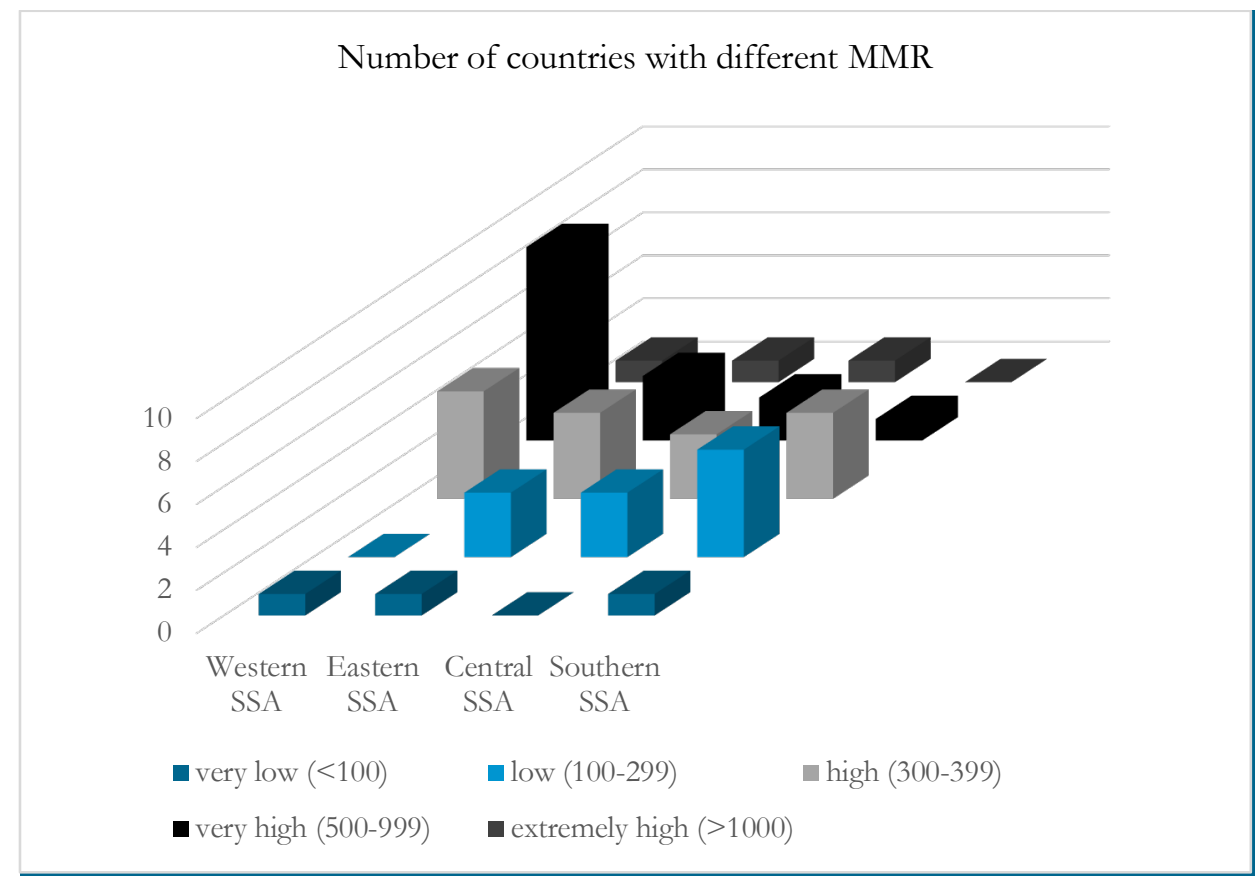

Figure 2: Maternal mortality ratio (MMR) by region in Sub-Saharan African (SSA) countries Source: WHOa, 2019: 99-104.

In addition to Nigeria, MMR was also very high in such more developed countries than Benin like Côte d'Ivoire (617). At the same time, the MMR remained high in 2017 (from 301 in Equatorial Guinea to 480 in Eritrea) in most of SSA countries 16; the Republic of Benin being one of them with 397 MD per 100,000 lb. Indeed, 14 SSA countries were able to achieve a reduction of MMR lower than $300-1$ in Western SSA (Cabo Verde - 58, very low), 4 in Eastern SSA (53 - very low in Seychelles to 295 - low in Sudan), 3 in Central SSA (130 in Sao Tome and Principe to 252 in Gabon - low) and 6 in Southern Africa (61 - very low in Mauritius to 289 - low in Mozambique). It is very important to emphasize that, despite the very low MMR in Mauritius in 2017, the country faced an increase in this parameter not only between 2000 (59) and 2017 (61) by 3.39 percent, but also between 2005 (53) and 2010 (66) by 24.53 percent, 2010 and 2015 (73) by 10.60 percent. Overall, from our point of view, an increase in MMR in Mauritius between 2000 and 2017 was so insignificant that it could not affect the quality of obstetric health care in general (WHOa, 2019: 99-104). 
The ARR between 2000 and 2017 in the Republic of Benin is shown on the fig. 3. During this period, the highest ARR was achieved in 2000 ( 9.72 percent), while the lowest - in 2003 (0.19 percent). The ARRs in the regions of SSA were low over the same period - 2.07 percent in Western, 2.24 percent in Central, 2.3 percent in Southern and 2.88 percent in the Eastern region, respectively. Among the SSA countries which achieved the highest ARRs between 2000 and 2017, there are Rwanda and Angola - 4.62 percent and 4.17 percent, respectively, while the lowest ARRs between 2000 and 2017 in SSA were observed in Lesotho and Côte d'Ivoire - 0.67 percent and 0.72 percent, respectively. We did not consider such countries with the lowest MMR in SSA like Mauritius (ARR = -3.39 percent) and Seychelles $(A R R=0)$ because they are categorized as having "achieved MDG 5A". The average ARR in the Republic of Benin between 1990 and 2015 was about 1.4, whereas between 2015 and 2017 it was about 2.8 percent. Taking into consideration an average ARR of 2.8 percent, then by 2030 probably the MMR in the country will be 252 or a little less. Achieving the SDG 3.1 target of MMR below 70 MD per 100,000 lb by 2030 in the Republic of Benin requires reducing MMR by at least 6.34 percent (a total of 82.4 percent is required) every year between 2017 and 2030, and in turn, this requires increasing current average ARR by 2.26 times and more (WHOa, 2019: 99-104). 


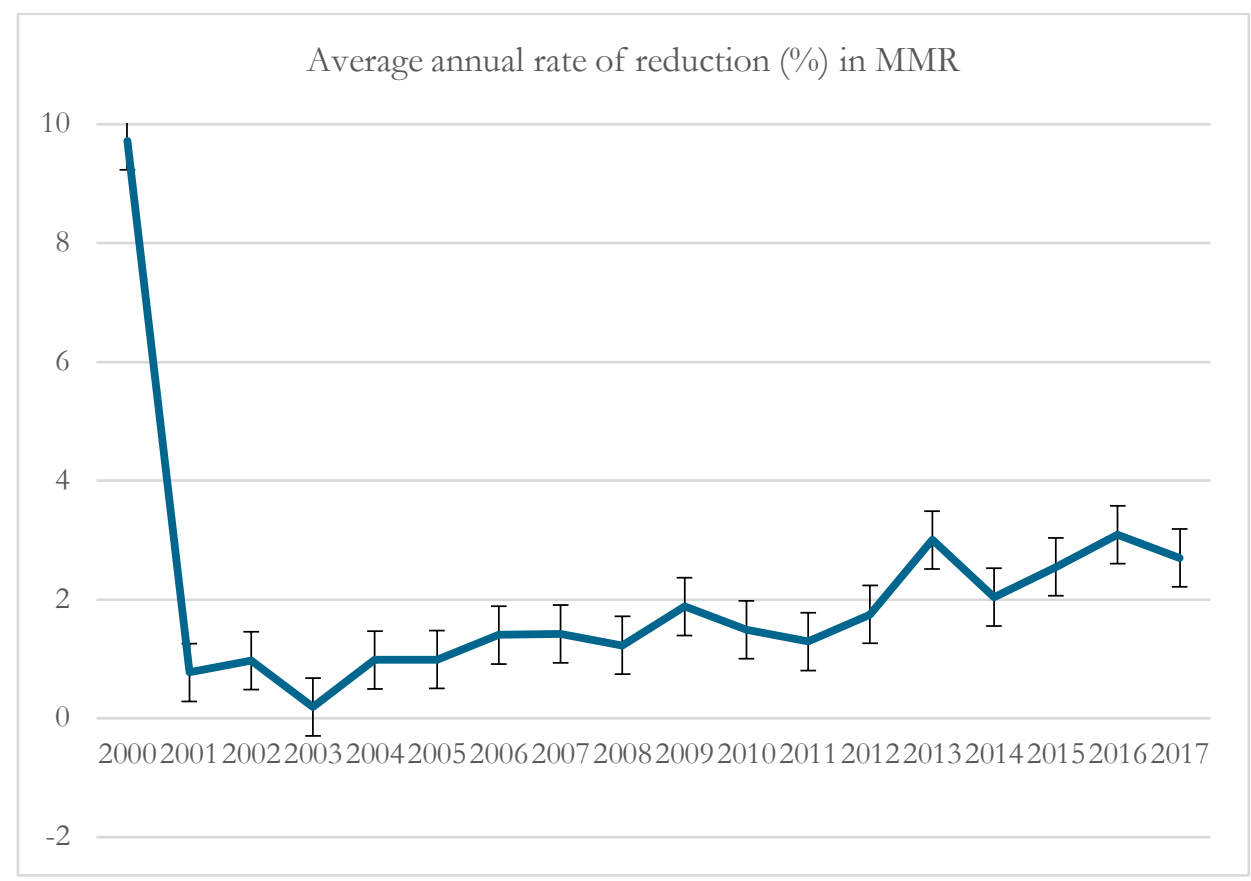

Figure 3: Average annual rate of reduction (\%) in maternal mortality ratio (MMR) in the Republic of Benin.

Source: WHO, 2019: 99.

Obviously, the average ARR in MMR is so low in SSA, especially in the Republic of Benin, that we can draw a sure conclusion on the impossibility to achieve the SDG 3.1 - reduction of MMR to less than 70 per 100,000 lb by 2030 in most SSA countries.

\section{$3 \quad$ Main causes of maternal death}

According to many different authors, socio-cultural and economic factors (poverty, educational disparities, cultural beliefs and practices), lack of skilled health care and personnel, late arrival of patients to the medical facilities and delay in consultation and provision of medical care (in some cases due to distance to facilities), their late transfer to the reference center, and lack of blood products are considered to be the most important factors contributing to or predisposing of MDs in SSA (Batist, 2019: 3; Yaya et al., 2018: 8; Zamané et al., 2018: 239). 
The most common direct causes of maternal injury and death are excessive blood loss (obstetric haemorrhage), infection, high blood pressure, unsafe abortion and obstructed labour, as well as indirect causes such as anaemia, malaria and heart disease (WHOb, 2019). The structure of MDs causes in SSA (in developing countries) is still mostly composed of such preventable and well treatable conditions like haemorrhage (mostly postpartum bleeding), pre-eclampsia (PE)/eclampsia and sepsis (postpartum and after abortion). Currently, in developed countries, amniotic fluid embolism, interrupted ectopic pregnancy by rupture of fallopian tube, and extragenital diseases (heart, renal diseases, etc.) are the most common causes of MDs.

We have compared the causes of MDs in the Republic of Benin and different countries (table 1). 
Table 1: Causes of maternal deaths in the World and different African countries

\begin{tabular}{|c|c|c|c|c|c|c|c|c|}
\hline \multirow{2}{*}{\multicolumn{2}{|c|}{ Causes }} & \multicolumn{6}{|c|}{ COUNTRIES } & \multirow[b]{2}{*}{ 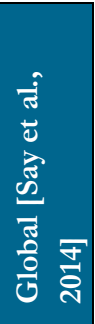 } \\
\hline & & 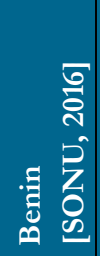 & 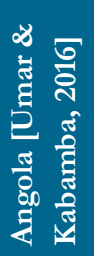 & 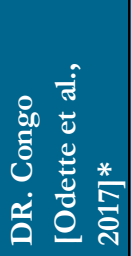 & 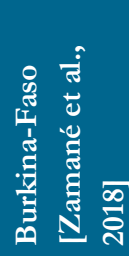 & 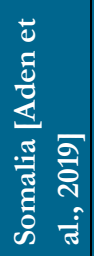 & 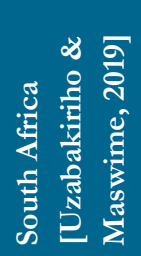 & \\
\hline \multirow{8}{*}{ 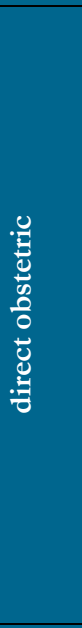 } & $\begin{array}{c}\text { obstetric } \\
\text { hemorrhage, } \\
\%\end{array}$ & 38.4 & 15 & 45.4 & 22.7 & 43.3 & 21 & 27.1 \\
\hline & eclampsia, $\%$ & 14.3 & 11 & 23.4 & 13.5 & 26.7 & 15 & 14 \\
\hline & $\begin{array}{l}\text { infection/ } \\
\text { sepsis, \% }\end{array}$ & 4.5 & 13 & 5.2 & 31.9 & 10 & 2 & 10.7 \\
\hline & $\begin{array}{l}\text { obstructed } \\
\text { labour, \% }\end{array}$ & 4.6 & NI & NI & NI & 13.3 & NI & NI \\
\hline & $\begin{array}{l}\text { ruptured } \\
\text { uterus, } \%\end{array}$ & 6.3 & 10 & NI & NI & NI & NI & NI \\
\hline & $\begin{array}{c}\text { ectopic } \\
\text { pregnancy, \% }\end{array}$ & 3.3 & 1 & NI & NI & NI & 4 & NI \\
\hline & abortion, $\%$ & 3.5 & 1 & $\mathrm{NI}$ & 3.5 & NI & 2 & 7.9 \\
\hline & other, $\%$ & 3.5 & NI & $\mathrm{NI}$ & NI & NI & $\mathrm{NI}$ & 12.8 \\
\hline 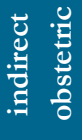 & anemia, $\%$ & NI & 13 & 3.9 & 17.8 & 6.7 & NI & NI \\
\hline \multirow{3}{*}{ 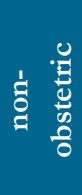 } & malaria, $\%$ & $\mathrm{NI}$ & 14 & 1.3 & 2.9 & $\mathrm{NI}$ & $\mathrm{NI}$ & \multirow{3}{*}{27.5} \\
\hline & HIV, \% & 1 & NI & 1.3 & & NI & 56 & \\
\hline & other, $\%$ & NI & 22 & 19.50 & 7.7 & NI & 2 & \\
\hline
\end{tabular}

NB: DR. Congo [Odette et. al., 2017]* - we have presented the statistics out of their effective number of 77 maternal deaths in the study. NI - no information.

The frequency of such preventable and well-treatable causes of MDs like obstetric haemorrhage (38.40 percent) and (PE)/eclampsia (14.30 percent) remains high in the country. The prevalence of obstetric haemorrhage in Benin is higher than worldwide - 27.1 percent (Say et al., 2014: e327) and that obtained by Zamanéet al. in Burkina-Faso (22.70 percent) (Zamané et al., 2018: 239), Uzabakiriho et al. in South Africa (21 percent) (Uzabakiriho \& Maswime, 2019: 413), Umar et al. in 
Angola (15 percent) (Umar \& Kabamba, 2016: 65). In contrast, obstetric haemorrhage in the structure of MD causes is less frequent in the Republic of Benin than in the Democratic Republic of Congo (DR Congo) (61.40 percent) (Odette et al., 2017: 4). Indeed, the prevalence of obstetric haemorrhage in the Republic of Benin is comparable to that in Somalia - 43.3 percent (Aden et al., 2019: 4).

The prevalence of eclampsia (14.3 percent) in the structure of the causes of MDs in the Republic of Benin was comparable to that in the study of Umar et al. in Angola (11 percent) (Umar \& Kabamba, 2016: 65), Zamané et al. in Burkina-Faso (13.5 percent) (Zamané et al., 2018: 239), Uzabakiriho et al. in South Africa (15 percent) (Uzabakiriho \& Maswime, 2019:413)a nd worldwide - 14 percent (Say et al., 2014: e327). In the DR Congo and Somalia eclampsia was 1.64 and 1.87 times higher responsible for $\mathrm{MD}$ than in the Republic of Benin - 23.4 percent, 26.7 percent and 14.3 percent, respectively. At the same time, the prevalence of infections/sepsis in the country (4.5 percent) was 2.4, 2.9 and 7 times below that worldwide (10.7 percent) (Say et al., 2014: e327) and in the studies of Umar et al. (13 percent) (Umar \& Kabamba, 2016: 65) and Zamané et al. (31.90 percent) (Zamané et al., 2018: 239), but was comparable to the result of Odette et al. - 5.2 percent (Odette et al., 2017: 4) and 2.25 times higher than in the study of south-African authors (2 percent) (Uzabakiriho \& Maswime, 2019: 413). We believe that the use of iron medications, reducing the rate of anaemia during pregnancy and postpartum bleeding and inflammatory complications, and prevention of malaria during pregnancy, plays an important role in such low prevalence of infections/sepsis in the country. Furthermore, in the country there are such direct obstetric causes of MD like rupture of the uterus, prolonged labour and ectopic pregnancy, accounting for 6.3 percent, 4.6 percent and 3.3 percent, respectively. In addition, non-obstetric medical causes of MDs in the Republic of Benin account for about 22 percent in total. Out of them, malaria, hepatitis, heart/renal diseases, and AIDs occupy an important place among all MDs causes. Particular emphasis should be placed on the effect of HIV (one of the non-obstetric medical causes) on maternal mortality in 2017, which appeared to be less pronounced than in earlier years in the Republic of Benin. HIV-related indirect MDs in 2017 in the country accounted for approximately 1 percent of all MDs compared with 2.5 percent in 2005, at the peak of the epidemic. 


\section{$4 \quad$ Adolescent pregnancy as a higher risk factor for maternal death}

Every year, an estimated 21 million girls aged 15-19 years in developing regions become pregnant and approximately 12 million of them give birth (Darroch et al., 2016: 6). At least 10 million of these pregnancies are unintended, and more than half of them end in induced abortion. Moreover, it is noteworthy that worldwide, approximately 2 million girls under the age of 15 years become pregnant every year (UNPFA, 2015: 7). Today in the Republic of Benin, the situation about MD is also complicated by pregnancies in adolescent girls aged 10-19 years. In the academic year 2018/2019, 1,122 pregnancies were reported among 290,845 schoolgirls aged 10-19 years in the country (Ayosso, 2019).

Several factors contribute to adolescent pregnancies and births: lack/absence of information and sex education, forced and early marriage, barriers to accessing contraception, sexual violence and harassment, socio-cultural context and the absence of necessary legislative measures (Plan International, 2018).

Each day, more than 41,000 girls worldwide are married while still children, often before they may be physically and emotionally ready to become wives and mothers (World Bank, 2017: 1). On average, more than one in three girls (36.6 percent) marry before turning 18, and almost one in five women between the ages of 18 and 22 had given birth before they turned 18 (World Bank, 2017: 4). Early marriage leads to a high birth rate in this vulnerable age group -9 out of 10 adolescent pregnancies occur in marriage (UNPFA, 2015: 8). The current demographic data show that even 4 percent of teenage girls under the age of 15 years are married in Benin (EDSB-V, 2018: 18).

The birth coefficient in adolescent girls in Benin is $108 \%$ On average, 20 percent of adolescent girls ( 24 percent in rural regions versus 15 percent in towns and cities) in the Republic of Benin already bear children. The number of childbearing girls increases rapidly with age from 2 percent at 15 years to 47 percent at 19 years old. On the other hand, the number decreases with an increase in the level of educationfrom 34 percent among non-schoolgirls to 19 percent among schoolgirls at primary school and 8 percent at secondary school (EDSB-V, 2018: 16-17). According to the statistics, in the Republic of Benin, the adolescent fertility rate (births per 1,000 girls ages 15-19) was 86 (World Bank, 2018) and the population of female aged 10-14/15- 
19 years was 678,522/589,507 (UNFPA, 2017) in 2017. Assuming the accuracy of these data from international institutions, then in the country the number of births in adolescent girls aged 15-19 years could be 50,697. Consequently, we expect that the total number of adolescent births in Benin (10-19 years old) may be about 60,000 or more, whereas 120,000 or more adolescent girls might become pregnant in a year. At the same time, based on the results of the Fifth Demographic and Health Survey (FDHS) in Benin in 2017-2018 - on average, 20 percent of adolescent girls in the Republic of Benin are already childbearing (EDSB-V, 2018:16). This data suggests we can expect to see about 253,000 adolescent births in 2017, and that about 500,000 adolescent girls aged 10-19 years, might get pregnant. We can explain this significant difference between the estimates based on World Bank, UNFPA and FDHS data by the targeted contingent included in the FDHS in Benin. The Survey was limited only to 15,928 females aged 15-49 years (EDSB-V, 2018: 7) and based on such a cohort we cannot arrive at any appropriate conclusions about the whole population.

The consequences of early (adolescent) and unintended pregnancies are not only health-related (increased risk of MD, especially for mothers younger than 15-16 years old, increased risk of adverse pregnancy and perinatal outcomes), but also educational (school dropout and absenteeism, lower educational attainment and outcomes), social (stigma and discrimination from family and/or community, linkages with early marriage in some contexts, or unable to marry in others, increased vulnerability to violence and abuse) and economic (lower family income, increased poverty, increased dependency ratio) (UNESCO, 2017: 13). According to several authors, there are increased risks of maternal and perinatal adverse outcomes among adolescent girls, resulting in an elevated risk of MD as compared to women aged 2024 years (Althabe et al., 2015: 9; Ganchimeg et al., 2014: 47). Complications during pregnancy and childbirth are the leading cause of death for 15-19 year-old girls globally (Neal et al., 2012: 1115). Every year, the 10.2 million unintended adolescent pregnancies result in an estimated 3.3 million unplanned births, 5.6 million abortions (3.9 million of which are unsafe) and 1.2 million miscarriages (Darroch et al, 2016: 10). Unsafe abortions contribute to maternal mortality, morbidity and lasting health problems. Adolescent mothers (aged 10-19 years) face higher risks for eclampsia, puerperal endometritis and systemic infections than women aged 20 to 24 years, and babies of adolescent mothers face higher risks of low birth weight, preterm delivery and severe neonatal conditions (WHO, 2020). Every year 70,000 adolescent girls die 
from complications of pregnancy and childbirth (Plan International, 2018). In the Republic of Benin, every fifth MD occurs in adolescent girls in a year - 320 deaths.

Prevention and perspectives for reducing maternal deaths in the Republic of Benin

Most deaths related to pregnancy and childbirth complications are avoidable, preventable and treatable with low-cost, targeted interventions, strategies and services, all of which are known and have been well understood in the medical profession and health systems for a long period of time.

To avoid MD, all the measures should start with the prevention of unwanted pregnancies. Family planning is one of the most critical means of preventing not only unwanted pregnancies but also many $\mathrm{MD}$, particularly in low-income countries.

In the Republic of Benin, contraceptive use is still very low. According to Yaya et al., the percentage of contraceptive use in Benin was 17.2 percent in 2006; however, reduced to 14 percent in 2016. Moreover, their results showed that women aged 3549 years had an increase in the odds of facility-based delivery, compared to women aged 15-19 years (Yaya et al., 2018: 5). This conclusion was supported by the FDHS, in which it was shown that among married women aged 15-49 years, only 16 percent used any method of contraception (12 percent used modern methods of contraception while 4percent used traditional methods). At the same time, the use of contraceptives among married adolescent girls aged 15-19 years was only 6.3 percent (EDSB-V, 2018: 19, 20). All women, including adolescent girls, need access to contraception, safe abortion services to the full extent of the law, and quality postabortion care. The observance of inter-pregnancy interval (IPI), defined as the time between two consecutive pregnancies, is another family planning parameter playing an important role in the prevention of adverse maternal and perinatal outcomes. The WHO recommends an interval of at least 24 months from live birth to the next pregnancy and at least six months following abortion (WHO, 2007: 2). A metaanalysis of 67 studies conducted in 62 countries, as well as an additional study from Brazil, revealed that poor maternal and perinatal outcomes were associated with IPIs between 6 and 18 months or longer than 59 months (Cecatti et al., 2008: 278). Furthermore, Smith et al. in 2009 concluded that women with birth-to-pregnancy intervals of less than five months experienced a risk of $\mathrm{MD}$ that was 2.5 times higher 
than women with birth-to-pregnancy intervals of 18 to 23 months (Smith et al, 2009: $5)$.

The WHO also has declared that all women need access to high-quality care both during pregnancy and during and after childbirth, and that it is particularly important that all births are attended by skilled health professionals, as timely management and treatment can make the difference between life and death for the mother as well as for the baby (WHOb, 2019). Intravenous administration of oxytocin in the third stage of labour effectively reduces the risk of bleeding and consequently of MD, as well as infection after childbirth, but can be dispensed with assuming that good hygiene is practised and if early signs of infection are recognized and appropriately treated in a timely manner. Also, PE should be detected and appropriately managed before the onset of convulsions (eclampsia) and other life-threatening complications. Administering drugs such as magnesium sulfate for PE can lower a woman's risk of developing eclampsia (WHOb, 2019). In order to prevent PE and then eclampsia, pregnant women with a high risk of developing PE should be prescribed 75-150 mg of acetylsalicylic acid daily from prior to 12 until 36 weeks of gestation (Romanenko \& Sulimenko, 2020: 495; WHO, 2011: 14).

In the Republic of Benin, great hope was placed on performing free Cesarean sections (CS), subsidized by the government, to reduce maternal and perinatal mortality. Alas, this measure only achieved a reduction in MMR of about 11 percent (an average ARR of about 1.6 percent) between 2010 (MMR = 446) and 2017 (MMR = 397) (WHOa, 2019: 99). From our point of view, the Decree № 2008-730 of December 22, 20081, signed by the President of the Republic of Benin and instituting the delivery of free CS in public, religious or associative hospitals/medical centers (approved by the Government of the Republic of Benin), did not achieve the desired results because the ARR in MMR remained low, despite its increase from 1.23 percent in 2008 to 3.09 percent in 2016. We explain this fact by the absence of perinatal risk's determination with a subsequent performance of elective CS, late hospitalization for emergency CS, financial difficulties pregnant women experience in purchasing the necessary medications used for the intervention because only the surgical intervention is offered free.

\footnotetext{
${ }^{1}$ Décret № 2008-730 du 22 décembre 2008 portant institution de la gratuité de la césarienne au Bénin. République du Bénin, Présidence de la République.
} 
To reduce MD, a particular emphasis should be placed on prevention of adolescent pregnancies. In view of this, the interventions according to WHO (2014: 2-7) must aim to:

- prevent early pregnancy:

- reduce marriage before age 18: prohibit early marriage, keep girls in school, influence cultural norms that support early marriage;

- create understanding and support to reduce pregnancy before age 20: to support pregnancy prevention programmes among adolescents, educate girls and boys about sexuality and to build community support for preventing early pregnancy;

- increase the use of contraception by adolescents at risk of unintended pregnancy: legislate access to contraceptive information and services, reduce the cost of contraceptives to adolescents, educate adolescents about contraceptive use, build community support for contraceptive provision to adolescents, enable adolescents to obtain contraceptive services;

- reduce coerced sex among adolescents: to prohibit coerced sex, empower girls to resist coerced sex, influence social norms that condone coerced sex, engage men and boys to critically assess norms and practices;

- prevent adverse reproductive outcomes:

- reduce unsafe abortion among adolescents;

- increase use of skilled antenatal, childbirth and postnatal care among adolescents.

The current laws in the Republic of Benin (Law № 2002-07 of August 24, $2004^{2}$ on the Family code and № 2015-08 of December 08, $2015^{3}$ on the Children's code in the Republic of Benin) completely prohibit not only an early (teenage) and forced marriage (both girls and boys under the age of 18 years), but also adolescent pregnancies, sexual violence and harassment. Moreover, these laws also envisage imprisonment for three to ten years and a fine of 100,000 XOF (153 EUR) to 500,000 XOF (762 EUR) for any parent/relative or person who gave in marriage a

\footnotetext{
${ }^{2}$ Loi № 2002-07 du 24 août 2004 portant Code des personnes et de la famille. République du Bénin, Présidence de la République.

${ }^{3}$ Loi № 2015-08 du 08 décembre 2015 portant code de l’enfant en République du Bénin. Présidence de la République.
} 
young girl and imprisonment for six months to two years and a fine of 100,000 XOF (153 EUR) to 200,000 XOF (306 EUR) for the male involved in an adolescent pregnancy.

Unfortunately, to date the application of these laws has been very poor. The government and social organizations must do more and as much as possible to enforce existing laws in order to bring offenders of these laws to justice.

Today, the law № 2003-04 of March 03, $2003^{4}$ on sexual and reproductive health in the Republic of Benin describes only the methods of contraception in its chapter 4 and article 16, but, unfortunately, does not define who is supposed to use these methods of contraception. Another critical deficiency in the present legislative framework is that there is no information about adolescents. The same chapter of this law in its Art. 17 clarifies that abortion is allowed only in cases when the pregnancy threatens the health and life of the pregnant woman, if the pregnancy occurs after rape or incestuous intercourse or if the fetus is diagnosed with a lifethreatening abnormality. This law does not also clarify criminal provisions penalizing the performance of illegal/criminal abortion.

\section{Conclusion}

Unfortunately, in the Republic of Benin, the existing legislative measures applied with the aim of reducing maternal deaths and adolescent pregnancies are insufficient both in terms of content and the lack of enforcement. Consequently, the maternal mortality ratio remains high with a low average annual rate of reduction in maternal mortality ratio. As our paper has demonstrated, most maternal deaths are preventable and their causes treatable, and the methods of reducing maternal mortality ratio even in the low-income conditions are well known. We believe that in order to reduce maternal deaths in the Republic of Benin it is critical that the following steps be taken. The public must be better educated and informed about the problem. We call this educational campaign one of public sensitization. The public must have better accessibility to medical facilities (building of new hospitals, especially with modern equipment), family planning (including both adolescent girls

\footnotetext{
${ }^{4}$ Loi № 2003-04 du 03 mars 2003relative à la santé sexuelle et à la reproduction,Présidence de la République.
} 
and boys), high-quality care in pregnancy, during and after childbirth (continuing/permanent education of personnel), the inclusion of the medications into the of free cesarean section set and strict application of the existing laws on health care coupled with legislative reform, to better deal with adolescents. The Government of the Republic of Benin must strengthen health care programs and policies and create strategies aimed at universal health coverage. While we recognize this is perhaps an ambitious agenda, if followed, Benin will reap great benefits, as has been the case in other countries, as the statistics amply demonstrate.

\section{Acknowledgements}

The publication has been prepared with the support of the "RUDN University Program 5-100".

\section{Disclosure statement}

No potential conflict of interest was reported by the author(s).

\section{References}

Althabe, F., Moore, J. L., Gibbons, L., et al. (2015) Adverse maternal and perinatal outcomes in adolescent pregnancies: The Global Network's Maternal Newborn Health Registry study, Reproductive Health, 12 (Suppl. 2), S8, doi: 10.1186/1742-4755-12-S2-S8.

Aden, J. A., Ahmed, H. J. \& Östergren, P. O. (2019) Causes and contributing factors of maternal mortality in Bosaso District of Somalia. A retrospective study of 30 cases using a Verbal Autopsy approach, Global Health Action, 12(1), 1672314, doi:10.1080/16549716.2019.1672314.

Ayosso, A (2019) Grossesses en milieu scolaire au Bénin: 1122 cas enregistrés au cours de l'année 2018-2019, retrieved from: https://www.24haubenin.info/?1-122-cas-enregistres-au-cours-de-1-annee2018-2019 (22 June 2020).

Batist, J. (2019) An intersectional analysis of maternal mortality in Sub-Saharan Africa: a human rights issue, Journal of global health, 9(1), 010320, doi: 10.7189/jogh.09.010320.

Cecatti, J.G., Correa-Silva, E.P., Milanez, H. et al. (2008) The associations between inter-pregnancy interval and maternal and neonatal outcomes in Brazil, Maternal and Child Health Journal, 12(2), pp. 275-281, doi:10.1007/s10995-007-0219-y.

Darroch, J. E., Woog, V., Bankole, A. et al. (2016) Adding it up: costs and benefits of meeting the contraceptive needs of adolescents (New York: Guttmacher Institute), pp. 6, 10, retrieved from: https://www.guttmacher.org/report/adding-it-meeting-contraceptive-needs-of-adolescents (2 October 2020).

EDSB-V (Cinquième Enquête Démographique et de Santé au Bénin) 2017-2018 (2018) Ministère du Plan et du Développement. Institut National de la Statistique et de l'Analyse Économique (INSAE) Cotonou - Bénin. ICF, Rockville - Maryland - USA, pp. 7, 16-20.

Evaluation rapide des besoins en soins obstétricaux et néonataux d'urgence (SONU) au Bénin en 2016 (2016) République du Bénin. Ministère de la santé. Direction de la santé de la mère et de l'enfant, pp. 54, 55.

Ganchimeg, T., Ota, E., Morisaki, N. et al (2014) Pregnancy and childbirth outcomes among adolescent mothers: a World Health Organization multicountry study, BJOG, 121(1), pp. 40-48, doi:10.1111/1471-0528.12630.

Neal, S., Matthews, Z., Frost, M., et al. (2012) Childbearing in adolescents aged 12-15 years in low resource countries: a neglected issue. New estimates from demographic and household surveys 
in 42 countries, Acta Obstetricia et Gynecologica Scandinavica, 91(9), pp. 1114-1118, doi:10.1111/j.1600-0412.2012.01467.x.

Odette, K.M., Moise, K.K., Blood, B.N.D., et al. (2017) Etiologies of maternal mortality in the Provincial Hospital Janson Sendwe in Lubumbashi (DR. Congo). Open Access Library Journal, 4(3), e3502, retrieved from: https://doi.org/10.4236/oalib.1103502 (25 June 2020).

Plan international (2018) Causes et conséquences des grossesses précoces,Report du 15 juin 2018, retrieved from: https://www.plan-international.fr/info/actualites/news/2016-09-23-causeset-consequences-des-grossesses-precoces (24June 2020).

Romanenko, T. G. \& Sulimenko, O. M. (2020) Prevention of preeclampsia in women with multiple pregnancy after assisted reproduction, Wiadomosci Lekarskie, 73(3), pp. 494-497.

Say, L., Chou, D., Gemmill, A. et al. (2014) Global Causes of Maternal Death: A WHO Systematic Analysis, Lancet Global Health, 2(6), p. e323-e333, doi: S2214-109X(14)70227-X.

Smith, R., Ashford, L., Gribble, J. et al. (2009) Family planning saves lives. Population Reference Bureau, In: Report. Fourth Edition(Washington), p. 5.

Umar, A.S.\&Kabamba, L. (2016) Maternal Mortality in the Main Referral Hospital in Angola, 20102014: Understanding the Context for Maternal Deaths Amidst Poor Documentation, International Journal of Maternal and Child health and AIDS, 5(1), pp. 61-71.

UNESCO (United Nations Educational, Scientific and Cultural Organization) (2017) Early and unintended pregnancy \& the education sector. Evidence review and recommendations (Paris), p. 13.

UNFPA (United Nations Population Fund) (2015) Girlhood, not motherhood: Preventing adolescent pregnancy. A guidance document (New York), p. 7-8.

UNFPA (United Nations Population Fund) (2017) Adolescents and youth dashboard - Benin, retrieved from: https://www.unfpa.org/data/adolescent-youth/BJ (22 June 2020).

Uzabakiriho, B.\& Maswime, S. (2019) Causes of maternal death at Natalspruit Hospital. Johannesburg, South Africa, South African Medical Journal, 109(6), pp. 412-414, doi:10.7196/SAMJ.2019.v109i6.13215.

World Bank (2017) Economic impacts of child marriage: Global synthesis brief (Washington), pp. 1, 4.

World Bank (2018) Adolescent fertility rate (births per 1,000 women ages 15-19) 1960-2018 - Benin, World, retrieved from:

https:/ / data.worldbank.org/indicator/SP.ADO.TFRT?end=2018\&locations=BJ1W\&start=1993 (27 June 2020).

WHO (World Health Organization) Health statistics and information systems: Maternal mortality ratio (per 100 000 live births), retrieved from: https://www.who.int/healthinfo/statistics/indmaternalmortality/en/ (18 June 2020).

WHO (World Health Organization) (2007) Report of a WHO technical consultation on birth spacing (Geneva), p. 2.

WHO (World Health Organization) (2011) Recommendations for prevention and treatment of pre-eclampsia and eclampsia (Geneva), p. 14.

WHO (World Health Organization) (2014) Preventing early pregnancy and poor reproductive outcomes among adolescents in developing countries: what the evidence says. A guidance document brief (Geneva), pp. 2-7.

WHO (World Health Organization) (2015) Trends in Maternal Mortality: 1990 to 2015. Estimates by WHO, UNICEF, UNFPA, World Bank Group and the United Nations Population Division (Geneva), pp. $70,71,75$.

WHOa (World Health Organization) (2019) Trends in maternal mortality: 2000 to 2017. Estimates by WHO, UNICEF, UNFPA, World Bank Group and the United Nations Population Division (Geneva), pp. x, 83, 99-104.

WHOb (World Health Organization) (2019) Report on maternal mortality, retrieved from: https://www.who.int/news-room/fact-sheets/detail/maternal-mortality (28 June 2020).

WHO (World Health Organization) (2020) Adolescent pregnancy. Report, retrieved from: https://www.who.int/news-room/fact-sheets/detail/adolescent-pregnancy (24 June2020).

Yaya, S., Uthman, O. A., Amouzou, A. et al. (2018) Inequalities in maternal health care utilization in Benin: a population based cross-sectional study, BMC Pregnancy Childbirth, 18(194), pp. 1-9, https://doi:10.1186/s12884-018-1846-6. 
Zamané, H., Sow, H. E., Kain, D. P. et al. (2018) Maternal Mortality at the Dori Regional Hospital in Northern Burkina Faso, 2014-2016, International Journal of Maternal and Child health and AIDS, 7(2), pp. 235-241.

\section{Legislation}

Law № 2002-07 of August 24, 2004 “On the persons and family Code”. Articles 119, 120, 123. The Republic of Benin. Presidency of the Republic, pp. 18, 19.

Decree № 2008-730 of December 22, 2008 "On the institution of free cesarean section in Benin". Articles 1-6. The Republic of Benin. Presidency of the Republic, pp. 1-2.

Law № 2015-08 of December 08, 2015 “On the children's Code in the Republic of Benin”. Articles 158, 180, 181, 331. The Republic of Benin. Presidency of the Republic, pp. 38, 43, 74. 
